\title{
Pancreas-specific RelA/p65 truncation increases susceptibility of acini to inflammation-associated cell death following cerulein pancreatitis
}

\author{
Hana Algül,, ${ }^{1}$ Matthias Treiber, ${ }^{1}$ Marina Lesina, ${ }^{1}$ Hassan Nakhai, ${ }^{1}$ Dieter Saur, ${ }^{1}$ \\ Fabian Geisler, ${ }^{1}$ Alexander Pfeifer, ${ }^{2}$ Stephan Paxian, ${ }^{3}$ and Roland M. Schmid ${ }^{1}$
}

\begin{abstract}
${ }^{1}$ Second Department of Internal Medicine, Klinikum rechts der Isar, Technical University of Munich, Munich, Germany. ${ }^{2}$ Institute of Pharmacology and Toxicology, University of Bonn, Bonn, Germany. ${ }^{3}$ Department of Neurology, Molecular Neurology Unit, University of Muenster, Muenster, Germany.
\end{abstract}

\begin{abstract}
Activation of the transcription factor NF- $\mathrm{B} / \mathrm{Rel}$ has been shown to be involved in inflammatory disease. Here we studied the role of RelA/p65, the main transactivating subunit, during acute pancreatitis using a Cre-loxP strategy. Selective truncation of the rela gene in pancreatic exocrine cells led to both severe injury of the acinar cells and systemic complications including lung and liver damage. Our data demonstrated that expression and induction of the protective pancreas-specific acute phase protein pancreatitis-associated protein 1 (PAP1) depended on RelA/p65. Lentiviral gene transfer of PAP1 cDNA reduced the extent of necrosis and infiltration in the pancreata of mice with selective truncation of RelA/p65. These results provide in vivo evidence for RelA/p65 protection of acinar cell death via upregulation of PAP1. Moreover, our data underscore the pancreas-specific role of $\mathrm{NF}-\kappa \mathrm{B} / \mathrm{Rel}$ and suggest multidimensional roles of $\mathrm{NF}-\kappa \mathrm{B} / \mathrm{Rel}$ in different cells and contexts during inflammation.
\end{abstract}

\section{Introduction}

Acute pancreatitis (AP) is a common clinical problem $(1,2)$. Approximately $25 \%$ of patients with AP develop a severe disease course that leads to systemic inflammatory response syndrome (SIRS) and sequelae such as multiorgan dysfunction syndrome (MODS) and acute respiratory distress syndrome (ARDS) with mortality rates up to $50 \%$. Although intra-acinar cell activation of digestive enzymes such as trypsinogen is likely to be the triggering event for acinar cell injury, the exact mechanisms that regulate the severity of AP are unknown (3-5).

An important reorganization of the gene expression pattern occurs during inflammation of the pancreas as part of a well-structured response to exogenous or endogenous damage. Digestive enzymes such as amylase and lipase are downregulated and newly synthesized proteins are overexpressed, including secretory proteins such as pancreatitis-associated protein 1 (PAP1; also known as peptide 23, Reg-2, or RegIII $\beta$ ) and islet neogenesis associated protein (INGAP) (6-8). PAP1, together with the isoforms PAP2 and PAP3, and the pancreatic stone protein (PAP/Reg) constitute a family of proteins that belong to the C-type lectin family (9). While the expression of PAP1 and the severity of cerulein-induced pancreatitis are strongly correlated, the physiological role of PAP1 remains unclear (10). Recently, a regulatory link between PAP1 and the transcription factor NF-KB/Rel was proposed $(11,12)$.

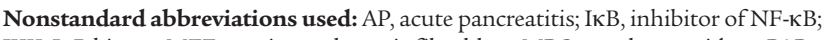
IKK, IкB kinase; MEF, murine embryonic fibroblast; MPO, myeloperoxidase; PAP, pancreatitis-associated protein; SDI, scrambled duplex siRNA; SIRS, systemic inflammatory response syndrome.

Conflict of interest: The authors have declared that no conflict of interest exists. Citation for this article: J. Clin. Invest. 117:1490-1501 (2007). doi:10.1172/JCI29882.
Activation of the transcription factor NF- $\mathrm{\kappa B} / \mathrm{Rel}$ is detectable very early in the course of experimental pancreatitis $(13,14)$. $\mathrm{NF}-\mathrm{\kappa B} /$ Rel is a key factor in the regulation of inflammation because of its ability to control the expression of numerous inflammatory mediators (15). Under resting conditions, NF- $\kappa \mathrm{B} / \mathrm{Rel}$ consists of a heterodimer of NF-кB1p50 and RelA/p65, which forms a complex with inhibitor of NF- $\kappa \mathrm{B} \alpha(\mathrm{I} \kappa \mathrm{B} \alpha)$ as a negative regulator of the complex that keeps NF-кB/Rel inactivated in the cytoplasm. Stimulatory factors including physical trauma, UV irradiation, mitogens, and cytokines such as TNF- $\alpha$ and IL- $1 \beta$ mediate hyperphosphorylation of the inhibitor protein I $\mathrm{B} \alpha$ via the kinase complex IкB kinase (IKK), which is followed by ubiquitination and subsequent proteasome-mediated degradation of the inhibitory protein (16). Subsequently, the NF-кB/Rel dimers translocate into the nucleus and bind specific $\kappa \mathrm{B}$ binding sites. In contrast to NF- $\kappa \mathrm{B} 1 \mathrm{p} 50$, RelA/p65 contains $\mathrm{C}$-terminal transactivation domains, which induce the transcription of genes encoding cytokines, chemokines, growth factors, and antiapoptotic factors (17).

Lack of specific inhibitors of the IKK/NF-кB/Rel signaling pathway, as well as lack of understanding the role of NF- $\mathrm{KB} / \mathrm{Rel}$ in different cellular compartments during inflammation, has been a limiting factor in previous studies. Here we report the pancreas-specific deletion of exons 7-10 of the rela gene, which encodes RelA/p65, in mice. A Cre-loxP system was used, because mice deficient for the rela gene are embryonic lethal due to TNF- $\alpha$-driven apoptosis of the developing liver (18). By flanking the region between exon 7 and exon 10 with 2 loxP recombination sites, we generated a conditional loss-of-function rela allele. Exons 7-10 encode the so-called Rel homology domain, which is important for DNA binding and dimerization of RelA/p65 (15). To direct Cre expression to the exocrine pancreas, we generated a knockin mouse with the gene encoding for Cre recombinase within the 

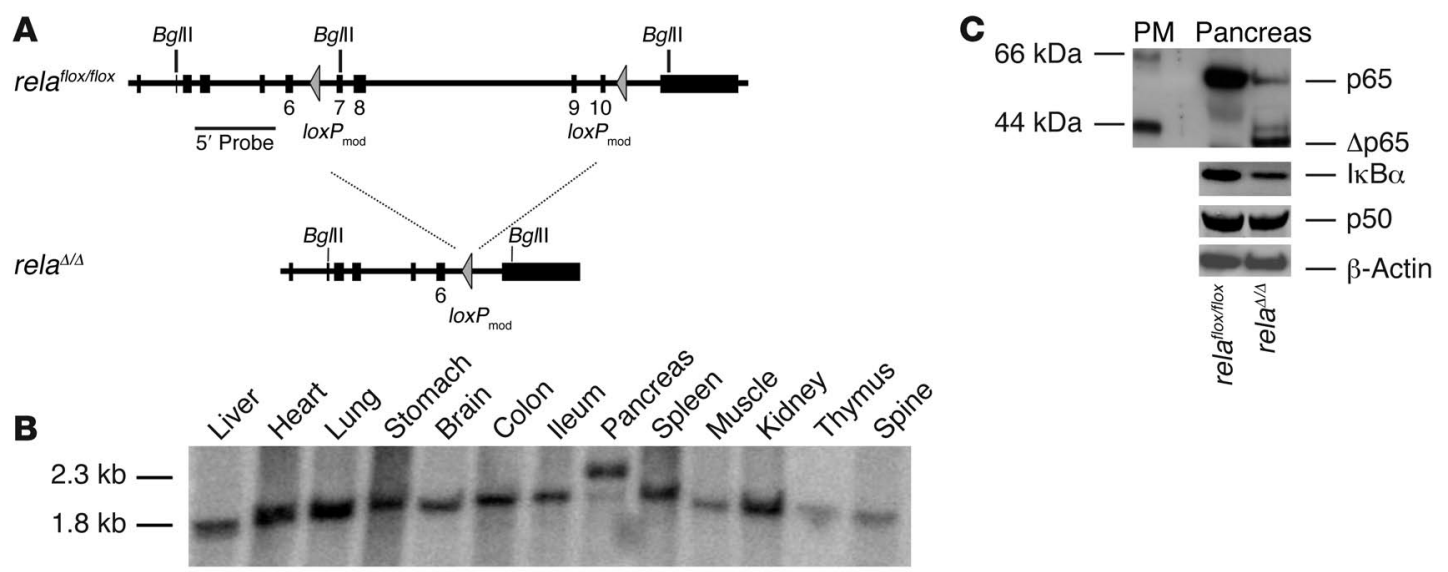

\section{Figure 1}

Pancreas-specific truncation of RelA/p65 using a Cre-loxP system. (A) Two identically oriented loxP sites (triangles) flank exons 7 and 10 of the rela gene. lox $P_{\text {mod }}$, modified loxP site. (B) Recombination of genomic DNA from the pancreata of rela ${ }^{\Delta / \Delta}$ mice was detected by Southern blot analysis using a probe external to the $5^{\prime}$ end of the targeting construct. No recombination was detected in the other organs. (C) Deletion of rela (exons 7-10) in the mouse pancreas was demonstrated at the protein level by Western blot of isolated acini from mice with the floxed allele in the presence or absence of Cre as indicated. In contrast to rela $a^{\text {flox/flox }}$ mice, rela ${ }^{\Delta / \Delta}$ mice display a truncated form of RelA/p65 ( $\left.\Delta \mathrm{p} 65\right)$. Pancreas protein extracts $(40 \mu \mathrm{g})$ were analyzed using antibodies against $\mathrm{p} 50, \mathrm{l} \mathrm{KB} \alpha$, and $\beta$-actin (as a loading control). The protein marker (PM) indicates the size of detected protein bands.

Ptf1a locus $(19,20)$. Cre-mediated deletion resulted in a functional inactive form of RelA/p65 in the pancreas, which does not dimerize or translocate to the nucleus. We found that truncation of RelA/p65 did not ameliorate the course of AP, but increased the susceptibility of acinar cells to inflammation-associated cell death and resulted in severe necrotizing pancreatitis with severe lung inflammation and liver damage. This unexpected phenotype was due, at least in part, to impaired induction of PAP1. Taken together, these data suggest a protective and organ-specific role of RelA/p65 in acute pancreatitis.

\section{Results}

Pancreas-specific truncation of RelA/p65 increases tissue damage during inflammation. To direct Cre expression to the exocrine pancreas, we generated a knockin mouse (Ptf1a-cre ${ }^{e x 1}$ ) with the gene encoding for the Cre recombinase within the Ptf1a locus (21). PTF1 is a heteromeric basic helix-loop-helix protein complex composed of 3 subunits: $\mathrm{p} 48, \mathrm{p} 64$, and $\mathrm{p} 75$. The tissue-specific component, $\mathrm{p} 48$, is essential for exocrine pancreatic development $(19,20)$. Thus expression of Cre resulted in the development of mice with pancreas-specific deletion of the floxed allele (exons $7-10$; rela ${ }^{\Delta / \Delta}$ mice; Figure 1, A and B) and accordingly in a truncated form of RelA/p65 in the pancreas (Figure 1C). The protein expression level of pancre-

\section{Figure 2}

Inhibition of nuclear translocation of RelA/p65 in the pancreas follow-

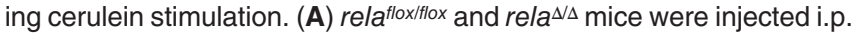
with $50 \mu \mathrm{g} / \mathrm{kg}$ cerulein at hourly intervals. Pancreatic nuclear protein extracts $(10 \mu \mathrm{g})$ at the indicated time points were subjected to gel retar-

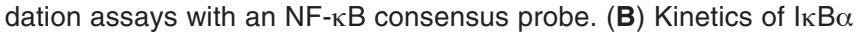
degradation in rela $a^{\text {flox/flox }}$ and rela ${ }^{\Delta / \Delta}$ mice were assessed by Western blot analyzing the protein content of $40 \mu \mathrm{g}$ of pancreatic whole-cell protein lysates using an antibody against IкB $\alpha$. Phosphorylated $I_{\kappa} B \alpha$ ( $\mathrm{p}-\mathrm{I} \kappa \mathrm{B} \alpha$; Ser32) was monitored by Western blotting using a phosphospecific antibody.

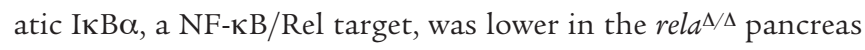
(Figure 1C). The expression level of p50, a subunit of the NF-kB/Rel heterodimer, was not altered in the rela ${ }^{\Delta / \Delta}$ pancreas. The rela ${ }^{\Delta / \Delta}$ mice developed normally with no signs of obvious dysfunction.

To analyze the function of RelA/p65 in AP, we induced AP by repetitive i.p. injections of sulfated cerulein, a decapeptide ana$\log$ of the pancreatic secretagogue cholecystokinin. Application of cerulein i.p. in relaflox/flox mice induced rapid and pronounced $\mathrm{NF}-\mathrm{\kappa B} /$ Rel activation as early as 30 minutes after the first injection

A

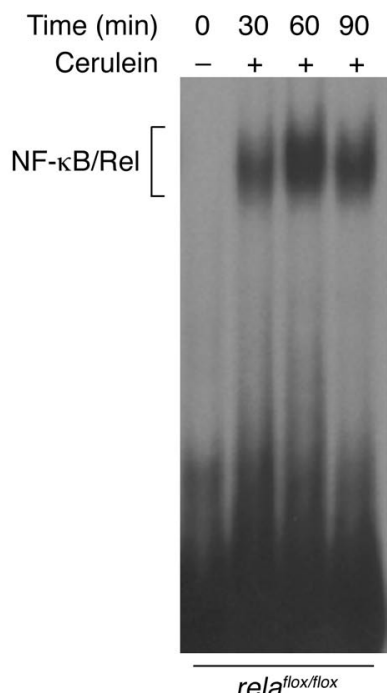

B Time (min) $\quad 0 \quad 30 \quad 60 \quad 90$

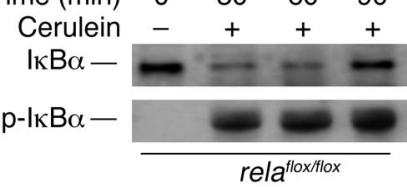

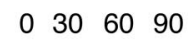

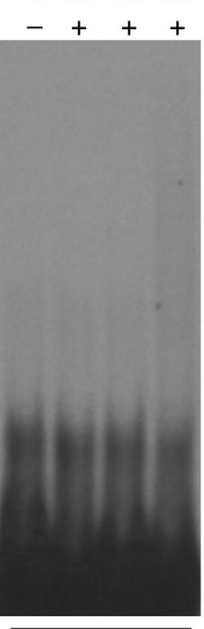

rela ${ }^{N / \Delta}$

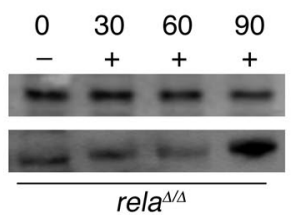


A

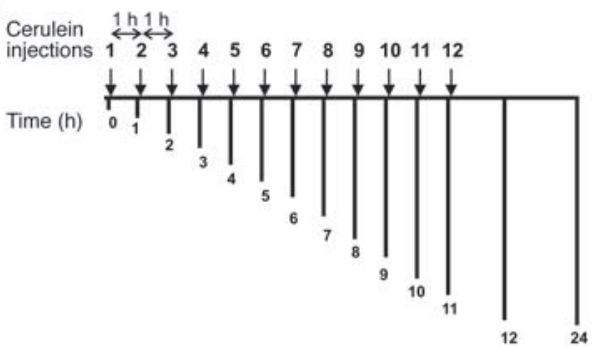
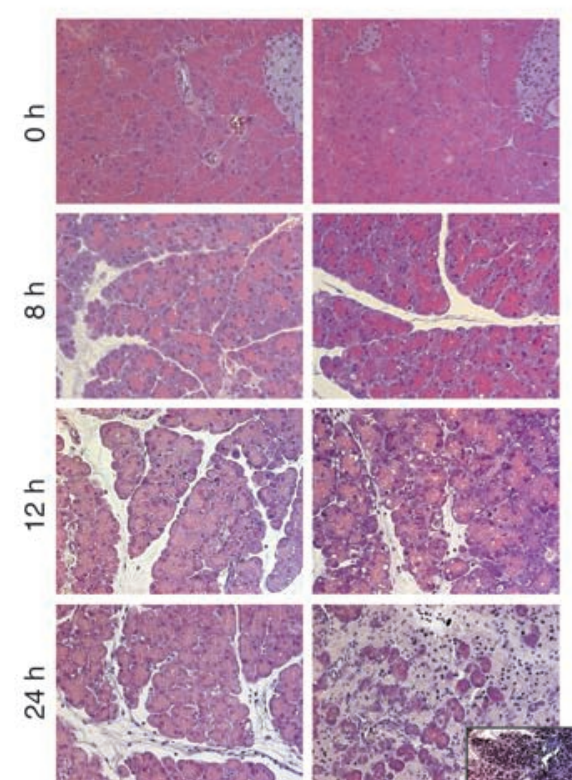

rela $a^{\text {floxhlox }}$

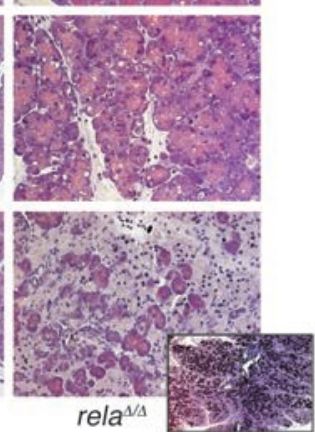

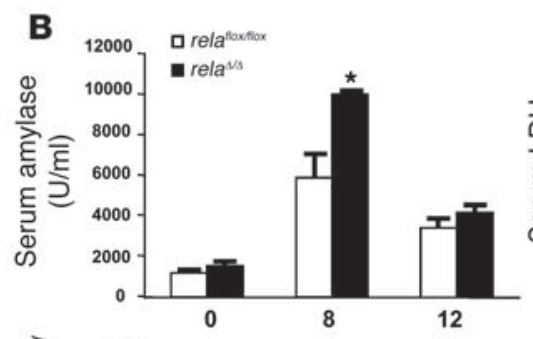
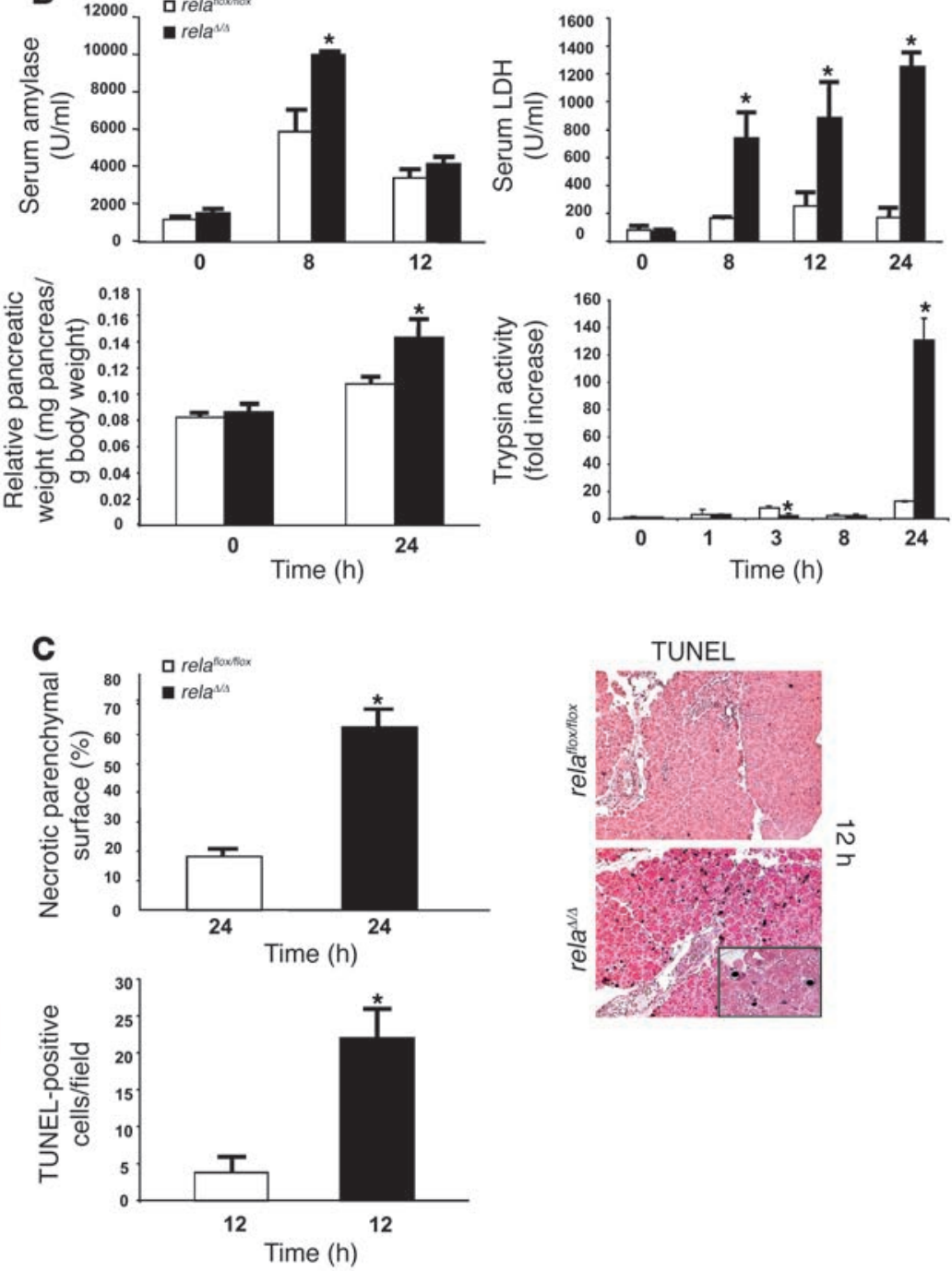

TUNEL

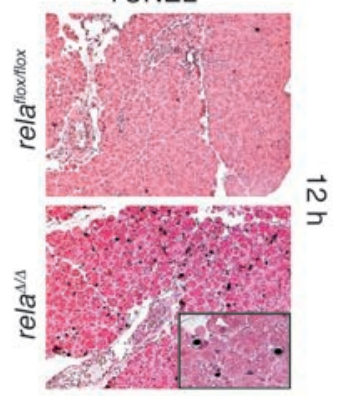

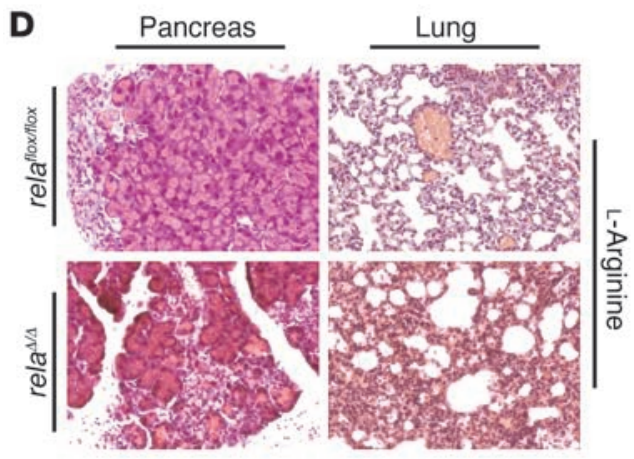
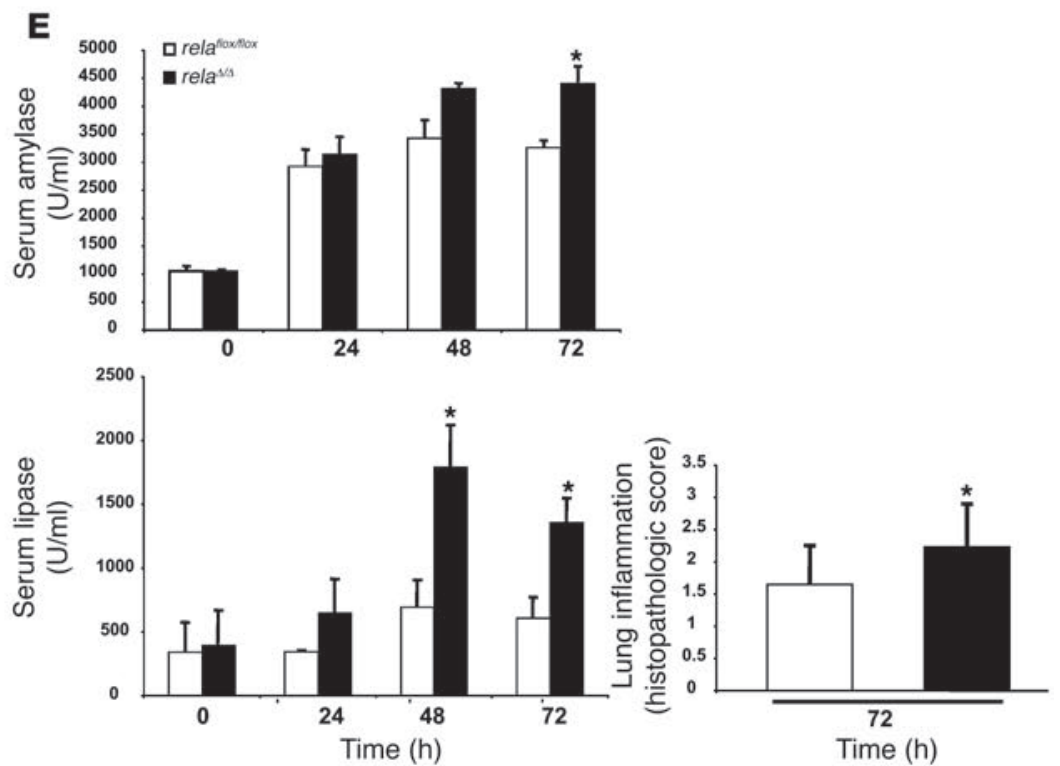


\section{Figure 3}

Pancreas-specific truncation of RelA $/$ p65 exacerbates AP. (A) rela flox/flox and rela ${ }^{\Delta / \Delta}$ mice were given 8 hourly i.p. injections of cerulein (50 $\mu \mathrm{g} / \mathrm{kg}$ ) and sacrificed 8,12 , or 24 hours after the first injection. Histological sections of rela flox/flox and rela ${ }^{\Delta / \Delta}$ mice were analyzed at the indicated time points. Note the increased vacuolization, morphologically apoptotic cells, ghost cells, edema, infiltration, and massive necrosis in the rela ${ }^{\Delta / \Delta}$ pancreata. (B) Pancreatic injury was determined by measuring amylase and LDH enzyme activity in serum. Total tissue homogenates were obtained from pancreata of cerulein-injected mice at the indicated time points and subjected to trypsin activity analysis. Pancreatic edema was determined indirectly by increase in pancreatic weight. (C) H\&E-stained pancreas sections from relaflox/flox and rela ${ }^{\Delta / \Delta}$ mice 24 hours after cerulein-induced inflammation were used to measure and quantify necrotic parenchymal surface area. TUNEL assay results are expressed as the apoptotic index of pancreata from mice with AP. Apoptotic cells exhibited black nuclei. (D) L-Arginine-induced pancreatitis was evaluated 72 hours after induction. Pancreata and lungs were removed for morphological analysis by H\&E. Note the appearance of focal necrosis in the pancreata of both groups. (E) Serum was removed for amylase and lipase evaluation at the indicated time points. Note the significant release of amylase and lipase into the serum in rela ${ }^{\Delta / \Delta}$ mice. Lung inflammation was evaluated as described in Methods. Values are mean \pm SD for independent animals $(n=5)$. ${ }^{*} P<0.05$ versus rela ${ }^{\text {flox/flox}}$. Original magnification, $\times 50$ (A, inset); $\times 200$ (A and D); $\times 100(\mathbf{C}$, inset); $\times 100$ (C).

(Figure 2A). In Ptfla-cre $e^{e x 1} \times$ relatlox/flox (i.e., rela ${ }^{\Delta / \Delta}$ ) mice, deletion of RelA/p65 abrogated NF-кB/Rel activity completely, suggesting that early activation of this transcription factor occurred in the exocrine pancreas. Degradation of the inhibitor protein followed the kinetics of NF-KB/Rel activation in relatlox/flox mice, while rela ${ }^{\Delta / \Delta}$ mice displayed a delayed but clear degradation (Figure 2B).

Pancreatitis in rela ${ }^{\Delta / \Delta}$ mice was analyzed at different time points after 8 i.p. injections of cerulein. Histology revealed that the nontransgenic wild-type, relaflox/flox, and Ptfla-cre $e^{e x 1}$ mice were identical, with typical morphological changes characterized by the appearance of edema, infiltrating cells, and acinar cell death (data not shown). Interestingly, each of these features was markedly increased in rela ${ }^{\Delta / \Delta}$ mice (Figure 3A). Eight hours after the first injection of cerulein, rela $a^{\Delta / \Delta}$ mice showed increased edema and acinar cells and the appearance of vacuolization and apoptotic morphology compared with relaflox/flox mice. The pancreata of rela ${ }^{\Delta / \Delta}$ mice contained large areas of necrotic tissue 24 hours after the onset of inflammation (Figure 3A, inset). The severity of pancreatitis was further characterized by significantly increased levels of serum amylase and serum LDH, edema formation, trypsinogen activation, and necrotic as well as apoptotic cell death in rela ${ }^{\Delta / \Delta}$ mice compared with littermate controls (Figure 3, B and C). In another model of pancreatitis, which was induced by 2 i.p. injections of L-arginine, truncation of RelA/p65 resulted in increased tissue damage. The rela $a^{\Delta / \Delta}$ mice developed significantly higher levels of serum amylase and serum lipase together with pronounced lung inflammation (Figure 3, D and E) (22). While none of the 4 mice in the control group died, 1 rela $a^{\Delta / \Delta}$ mouse died 48 hours after induction of pancreatitis (data not shown).

Activation of MAPK modules including ERK1/2, p38, and SAPK are induced rapidly and transiently during acute experimental pancreatitis in rodents (23). These modules are generally believed to be part of the cellular stress response machinery in the onset of inflammation in the pancreas. Interestingly, murine embryonic fibroblasts (MEFs) deficient for RelA/p65 display strong and prolonged activation of MAPK modules, which causes apoptosis and necrosis (24). Therefore we tested the kinetics of these MAPK modules during acute pancreatitis in both mouse lines. As shown in Figure 4, ERK1/2 (p42/44), p38, and SAPK (p46/54) remained phosphorylated upon cerulein stimulation in vivo even after 24 hours. This mechanism might contribute to the necroapoptotic cell death observed in rela $a^{\Delta / \Delta}$ mice and support previous studies concerning the role of MAPK modules during AP (25-31).

Inflammation was visualized and measured by the extent of infiltration of granulocytes using immunohistochemistry and myeloperoxidase (MPO) activity assays (Figure 5, A and B). These infiltrating cells likely produced high levels of pancreatic TNF- $\alpha$ (Figure 5, C and D). In contrast, pancreatic TNF- $\alpha$ appeared to originate from acinar cells in littermate controls (Figure 5D). Collectively, these data suggest that inhibition of early NF- $\mathrm{KB} / \mathrm{Rel}$ in acinar cells results in severe local inflammation with increased cell death that is independent of early increased trypsin activity. Furthermore, these findings support the hypothesis that acinar cells produce proinflammatory cytokines during pancreatitis and that this cytokine production requires RelA/p65.

Induction of PAP1 is impaired during pancreatitis in the rela ${ }^{\Delta / \Delta}$ pancreas. To identify the genes responsible for the RelA/p65-mediated protective effect in the pancreas, we performed microarray analysis and real-time PCR. The pancreas-specific acute phase protein PAP1 was downregulated in resting pancreas and was not induced following acute experimental pancreatitis in rela ${ }^{\Delta / \Delta}$ mice (Figure $6, \mathrm{~A}$ and $\mathrm{B}$ ). In contrast, previous studies showed that PAP1 was induced during pancreatitis and correlated with its severity $(6,10)$. We generated an antibody to an $\mathrm{N}$-terminal peptide sequence of murine PAP1 in rabbits and then immunoblotted pancreatic protein lysates to determine the expression level of PAP1 (Supplemental Figure 2; supplemental material available online with this article; doi:10.1172/JCI29882DS1). While PAP1 was induced 12 hours after the first injection of cerulein and peaked after 24 hours in littermate controls, the induction of PAP1 was virtually absent in rela ${ }^{\Delta / \Delta}$ mice (Figure 6C).

Next, we determined whether the lack of functional RelA/p65 in the pancreas was responsible for the impaired induction of PAP1. Promoter analyses revealed 2 putative $\kappa B$ sites upstream of the

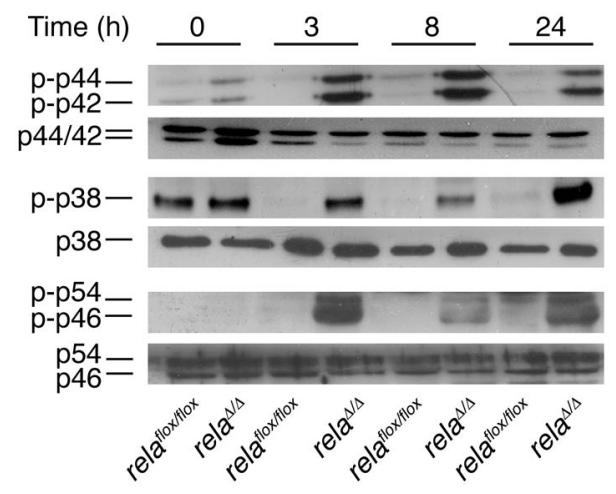

\section{Figure 4}

Analysis of MAPK modules during cerulein-induced pancreatitis. Pancreata were removed at the indicated time points. Whole-cell lysates $(30 \mu \mathrm{g})$ were blotted against phosphorylated p42, p44, p38, p46, and p54 and their respective unphosphorylated proteins. 
A

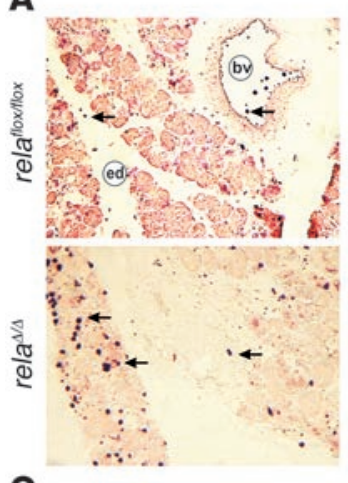

C
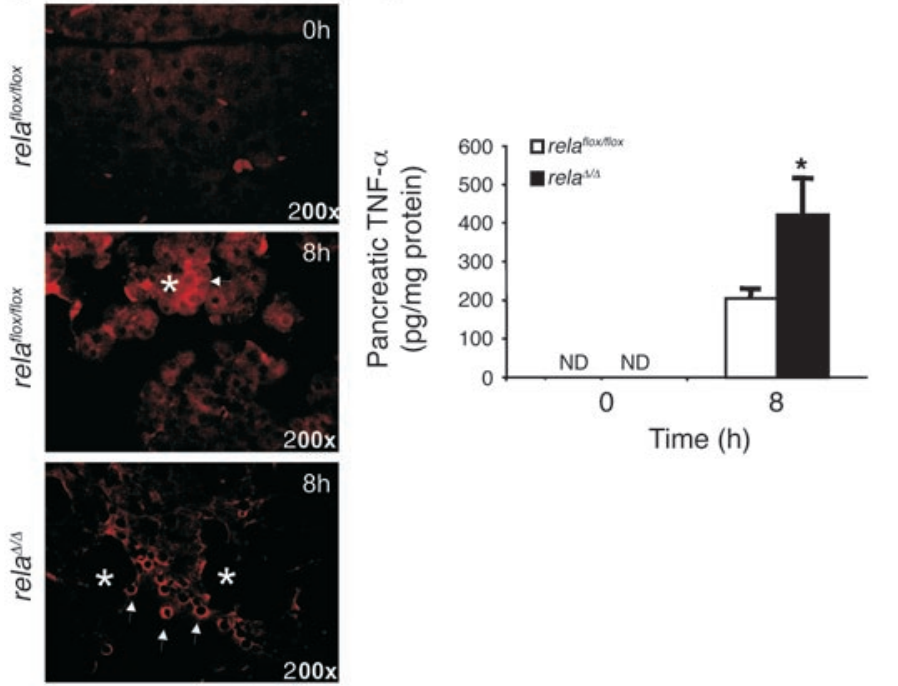

\section{Figure 5}

Increased infiltration and TNF- $\alpha$ production in the pancreata of rela ${ }^{\Delta / \Delta}$ mice. (A) Mononuclear infiltration into the pancreas was visualized by immunohistochemical detection of granulocytes using a Gr-1 antibody. bv, blood vessel; ed, edema. Original magnification, $\times 100$. (B) Pancreatic MPO

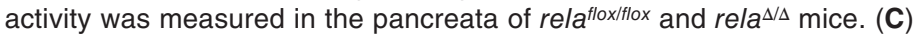
Infiltrating cells produced and released TNF- $\alpha$. Pancreata from ceruleintreated rela flox/flox and rela ${ }^{\Delta / \Delta}$ mice were stained using antibody to TNF- $\alpha$. Arrowheads indicate TNF- $\alpha$ accumulation; asterisks indicate acinar cells. Original magnification, $\times 200$. (D) TNF- $\alpha$ levels were measured by ELISA in pancreatic cell lysates from relafloxflox and rela $\mathrm{a}^{\Delta / \Delta}$ mice following 8 hourly injections of $50 \mu \mathrm{g} / \mathrm{kg}$ cerulein. ND, not detected. Values are mean \pm SD for independent animals $(n=4) .{ }^{\star} P<0.05$ versus rela ${ }^{\text {floxfflox}}$.

TATA box of the PAP1 gene, which could be a target of nuclear RelA/p65. To directly analyze the interaction of RelA/p65 with the PAP1 promoter/enhancer region, chromatin immunoprecipitations with a RelA/p65 antibody were performed on pancreas lysates at various time points following induction of inflammation. As shown in Figure 6D, RelA/p65 recruitment to the $\kappa B 1$ site in the PAP1 promoter was evident in control mice, with a peak at 24 hours after the onset of pancreatitis. In rela ${ }^{\Delta / \Delta}$ mice, RelA/p65 was not recruited to the promoter of PAP1. Thus, this recruitment was specific. The $\kappa \mathrm{B} 2$ site was not targeted by RelA/p 65 protein in either type of mice (Figure 6D). Immunohistochemical analysis of the pancreatic tissues from relatox/flox mice showed localized PAP1 expression at the apical regions of acini, which is typical for secretory proteins. No PAP1 expression was detected in the pancreata of rela $a^{\Delta / \Delta}$ mice 12 or 24 hours after cerulein injections (Figure $6 \mathrm{E}$ ). Taken together, these data indicate that PAP1 regulation is impaired in the rela $a^{\Delta / \Delta}$ pancreas.

PAP1 is involved in acinar cell death during pancreatitis. To clarify whether the extent of tissue damage during $\mathrm{AP}$ is regulated by overexpression of PAP1, we used siRNA to knock down PAP1 expression during inflammation in control littermates (32). First, we tested the ability of i.p. injected siRNA to penetrate the pancreas by using FITC-marked constructs (Supplemental Figure 3, A-D). Large areas of the liver and most of the pancreatic acinar cells were targeted with FITC-marked siRNA. Second, we tested 2 different siRNAs for their ability to inhibit cerulein-induced overexpression of PAP1 in vivo. Scrambled duplex siRNA (SDI) or specific siRNAs (PAP1 90 and PAP1 288) were administered to mice, which were then subjected to cerulein-induced pancreatitis (Figure 7A). PAP1 288 reduced PAP1 overexpression by nearly $80 \%$, while PAP1 90 reduced PAP1 overexpression by 40\% (Figure 7B and Supplemental Figure 3, E and F). Specific and nonspecific siRNAs did not substantially alter early NF-KB/Rel activation, as assessed by EMSA (Figure 7C). Mice that received PAP1 288 displayed a worse histology phenotype, with extensive areas of necrosis and increased LDH serum levels, compared with mice treated with SDI or PAP1 90 (Figure 7, $\mathrm{D}$ and $\mathrm{E})$. MPO activity levels in the pancreas were also higher in mice pretreated with PAP1 288 (Figure 7F). These data suggest that interference with PAP1 expression promotes a course of pancreatitis with increased severity.

We next investigated whether delivery of PAP1 cDNA into rela $a^{\Delta / \Delta}$ mice could attenuate the severity of AP. Therefore, we generated lentivirus vectors that contain the full-length murine PAP1 cDNA. A lentivirus containing the lac $Z$ gene served as control. We treated relafloxfflox and rela ${ }^{\Delta / \Delta}$ mice according to an established schedule (Figure 8A and Supplemental Figure 4). Pancreatic homogenates were analyzed for PAP1 expression 12 hours after the first cerulein injection. Cell death was evaluated morphologically 12 and 24 hours after the first injection of cerulein. Immunoblots confirmed that lentiviral gene transfer of PAP1 in rela $a^{\Delta / \Delta}$ mice resulted in protein levels comparable to those following cerulein-induced pancreatitis in littermate controls. Transfer of the lac $Z$ gene did not alter the basal expression levels of PAP1. Transfer of the lac $Z$ gene into relafox/flox littermates similarly had no effect on PAP1 protein levels (Figure 8B). Morphologically, littermate controls infected with the lac $Z$ gene exhibited the normal features of pancreatitis similar to vehicle controls. While rela ${ }^{\Delta / \Delta}$ mice displayed numerous TUNEL-positive cells (Figure $8 \mathrm{C}$ ), the differences between treatment with lentiviral PAP1 or with $l a c Z$ in $\mathrm{rel}^{\Delta / \Delta}$ mice were not statistically significant. Interestingly, rela ${ }^{\Delta / \Delta}$ mice infected with lentiviral PAP1 displayed reduced areas of necrosis, indicating that PAP1 partially rescued the necrotic phenotype (Figure 8D). Morphologically, lentiviral expression of PAP1 in rela $a^{\Delta / \Delta}$ mice slightly decreased the characteristic lung inflammation. This might be simply a manifestation of the more severe pancreatitis in rela ${ }^{\Delta / \Delta}$ mice.

These results indicate that RelA/p65 is involved in the transcriptional regulation of the acute-phase protein PAP1. Furthermore, upregulation of PAP1 was crucial for the protection of acinar cells following cerulein-induced pancreatitis. PAP1 had no significant effect on apoptosis, while it significantly reduced necrotic cell 
A

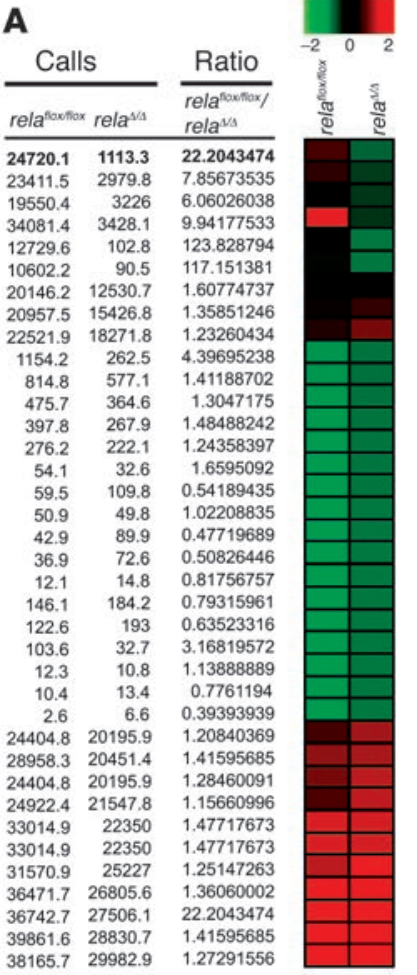

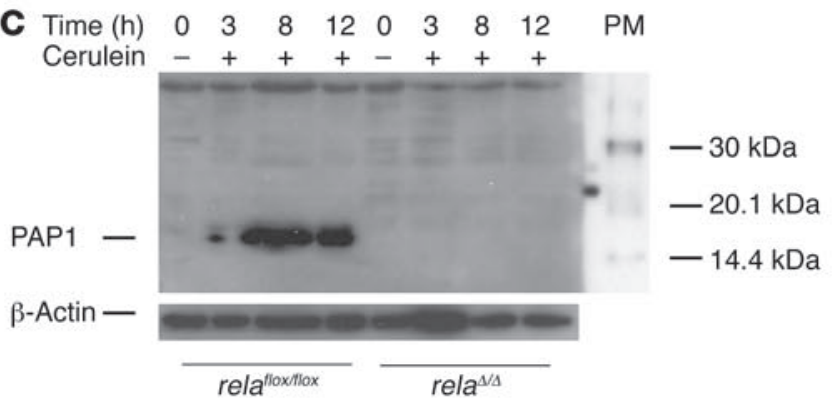

1416139_at regenerating islet-derived 2

1448872_at regenerating islet-derived 3 gamma

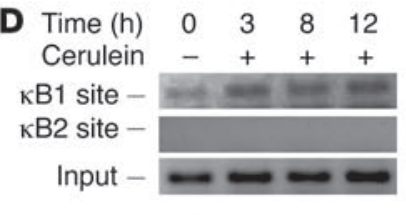

relatloxilox $\begin{array}{llll}0 & 3 & 8 & 12\end{array}$

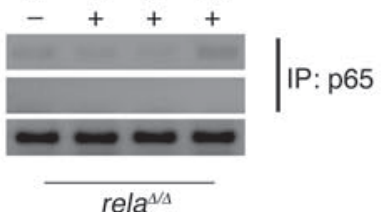

1416297_s_at pancreatitis-associated protein

1422682_s_at trypsinogen 16

1450689_at trypsin 3

1449495_at regenerating islet-derived 3 alpha

1416626_at phospholipase A2, group IB, pancreas

1437015_x_at phospholipase A2, group IB, pancreas

1431808_a_at inter alpha-trypsin inhibitor, heavy chain 4

1419424_at pancreas specific transcription factor, 1a

1424758 s at serine (or cysteine) proteinase inhibitor, clade A (alpha-1 antiproteinase, antitrypsin), member 10

1454837_at Mus musculus 10 day old male pancreas CDNA, RIKEN full-length enriched library

1417618 at inter-alpha trypsin inhibitor, heavy chain 2

1422271 at pancreatic polypeptide receptor 1

1420388_at protease, serine, 12 neurotrypsin (motopsin)

1417973_at inter-alpha trypsin inhibitor, heavy chain 1

1433949 X_at phospholipase A2, group IB, pancreas

1433948_at phospholipase A2, group IB, pancreas

1426558_x_at Mus musculus adult pancreas islet cells cDNA. RIKEN full-length enriched libran

1450144_at phospholipase A2, group IB, pancreas, receptor

1449123_at inter-alpha trypsin inhibitor, heavy chain 3

1454145_at phospholipase A2, group IB, pancreas, receptor

1421091_at_serine (or cysteine) proteinase inhibitor, member 12

1420440_at pancreatic polypeptide

1451597_at airway trypsin-like protease precursor

1416055 at amylase 2, pancreatic

1415777_at pancreatic lipase related protein 1

1415954_at trypsin 4

1438612_a_at colipase, pancreatic

1431763_a_at chymotrypsin-like

1431763_a_at chymotrypsin-like

$1435012 \times$ at elastase $3 B$, pancreatic

1448281 a_at elastase 2

1415905_at regenerating islet-derived 1

1416523_at ribonuclease, RNase A family, 1 (pancreatic 1423693_at elastase 1, pancreatic

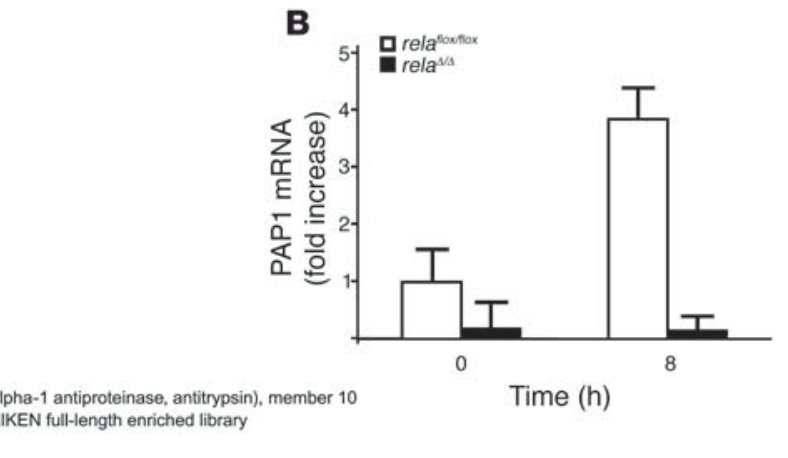


A

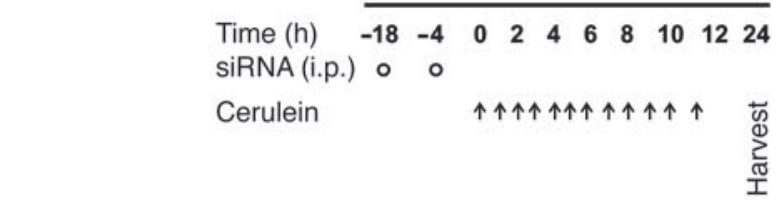

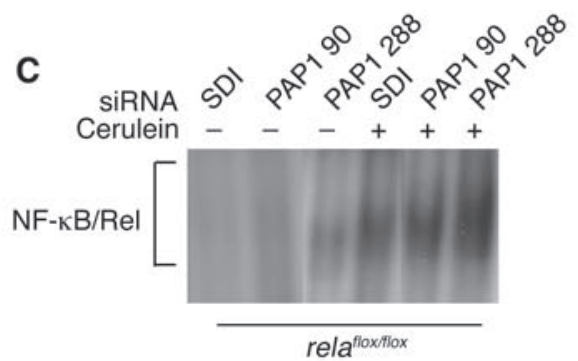

rela floxhlox
D

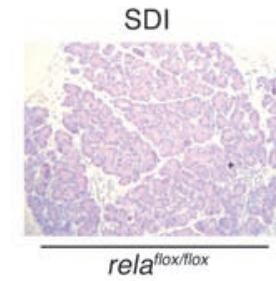

PAP1 90

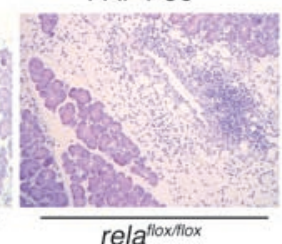

PAP1 288

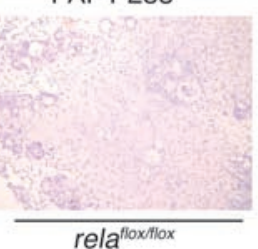

E

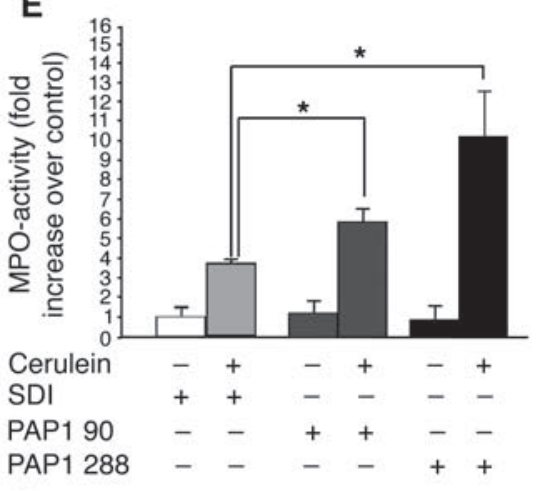

F

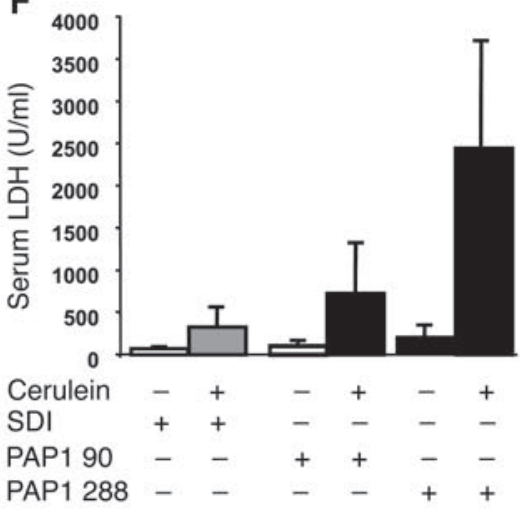

Figure 7

Inhibition of the protective effect of PAP1 using PAP1 knockdown in vivo. (A) Three age- and sex-matched relatlox/flox mice were injected with SDI or PAP1 siRNA (PAP1 90 and PAP1 288) twice in an 18-hour interval (circles) and then were subjected to cerulein-induced pancreatitis (arrows). (B) Pancreatic homogenates from mice as in A were obtained and immunoblotted for PAP1. Blotting for ERK1/2 protein was used as a loading control. (C) rela flox/flox mice were pretreated with specific and nonspecific siRNA as in A and subsequently injected with 1 i.p. dose of $50 \mu \mathrm{g} / \mathrm{kg}$ cerulein. One hour after injection, pancreatic nuclear protein extracts $(10 \mu \mathrm{g})$ were subjected to gel retardation assays with an NF-kB consensus probe. (D) Representative H\&E staining of pancreata from mice treated as in A. Note the increase in infiltration and massive necrosis in mice with PAP1 knockdown. (E and F) Pancreatic injury was measured by determining the enzyme activity of MPO in the pancreas (E) and LDH in the serum $(\mathbf{F})$. Values are mean \pm SD for independent animals $(n=3) .{ }^{*} P<0.05$.

and causes ARDS in humans. In order to determine the systemic inflammatory response following pancreatitis in our mouse model, we studied serum levels of IL-6, morphological changes in the lung, and the degree of leukocyte infiltration to the lung. While the expression levels of wild-type RelA/p65 in the lung remained unaffected in both mouse lines (Figure 9A), the morphological appearance following AP displayed obvious differences. In contrast to littermate controls, rela ${ }^{\Delta / \Delta}$ mice exhibited severe inflammation of the lungs as indicated by alveolar fluid accumulation and progressive thickening, hyperemia, and neutrophil infiltration of the interalveolar tissue (Figure 9, B-H). Serum levels of IL-6 were significantly higher in rela ${ }^{\Delta / \Delta}$ mice than in littermate controls (Figure 9I). Extensive lung inflammation and the subsequent reduced oxygenation of the blood produced morphological changes of the liver including centrilobular cell swelling with small vacuoles and fatty deposits, probably a result of disturbed $\beta$-oxidation (data not shown). From these data, we conclude that deletion of the rela gene (exons 7-10) in the pancreas resulted in SIRS.

\section{Discussion}

Using a genetic approach, we demonstrated that truncation of RelA/p65 in acinar cells did not ameliorate the course of AP, but provoked a severe necrotic AP characterized by extensive cell death, mononuclear infiltration, and signs of both MODS and ARDS. Therefore, our results clearly challenge the current view of the role of NF- $\mathrm{KB} / \mathrm{Rel}$ in the initiation and course of $\mathrm{AP}$ and demonstrate a protective and organ-specific role of endogenous RelA/p65 during AP (Figure 10).

Our data provide unambiguous and clear proof that endogenously activated NF- $\mathrm{B} / \mathrm{Rel}$ in acinar cells is not just an indicator of a cellular stress response, but plays a crucial role in limiting tissue injury and spread of the inflammatory response in the cerulein pancreatitis model. While induction of apoptotic cell death has been suggested to improve the outcome in AP, acinar cell necrosis results in a serious course of $\mathrm{AP}(33-37)$. In our model, the increase in necrosis was far greater than the induction of apoptosis. The mechanism by which the decision between apoptosis and necrosis is arbitrated is not well understood. NF- $\mathrm{KB} /$ Rel may act as a switch in the decision process in acinar cells. This effect seems to be cell specific. Wild-type MEFs are resistant to TNF- $\alpha$-induced cell death. Upon TNF- $\alpha$ stimulation, MEFs that are deficient for RelA/p65 display signs of apoptotic cell death but predominantly display features of necrosis, specifically the loss of membrane integrity without apparent damage of nuclei. Thus, necrosis was proposed to be a result of intracellular accumulation of ROS, which mediate pro- 
A

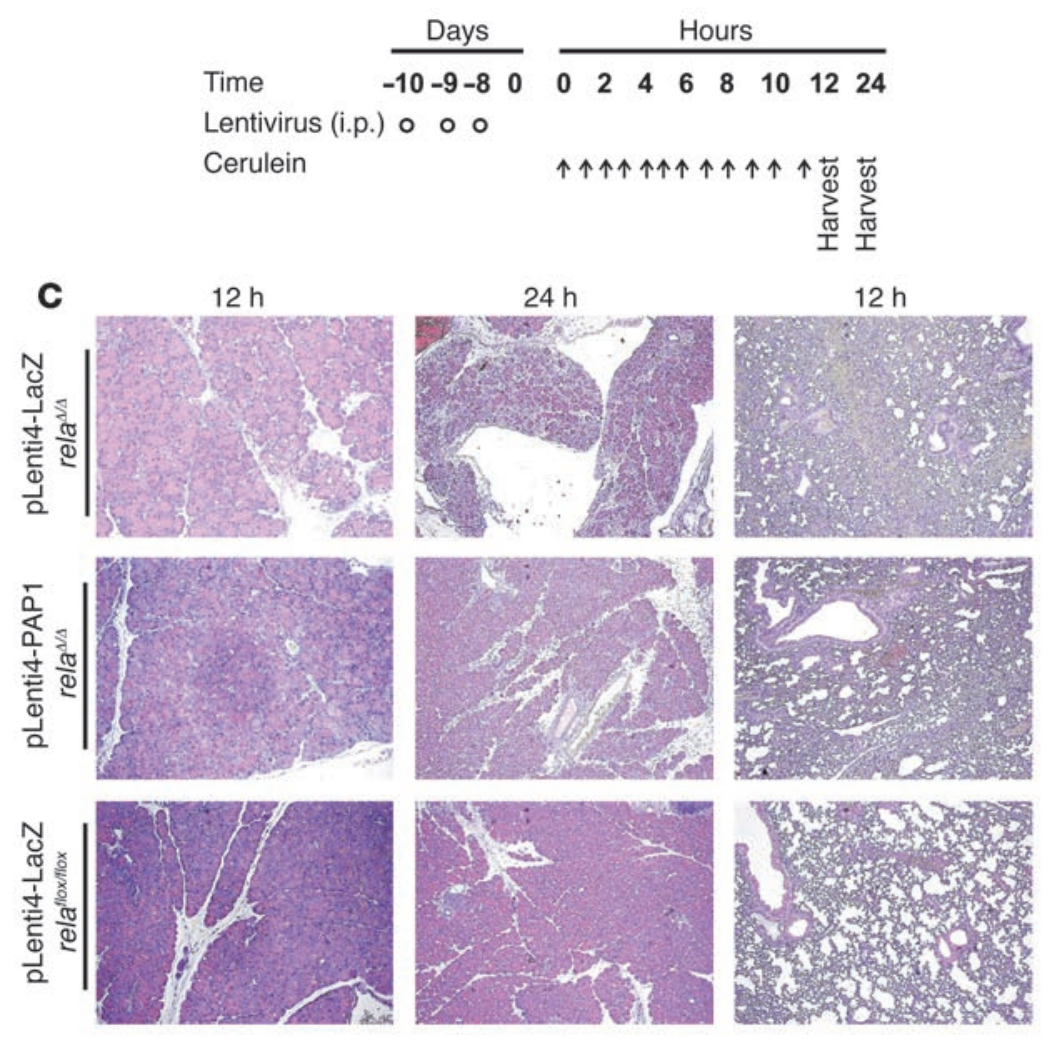

B
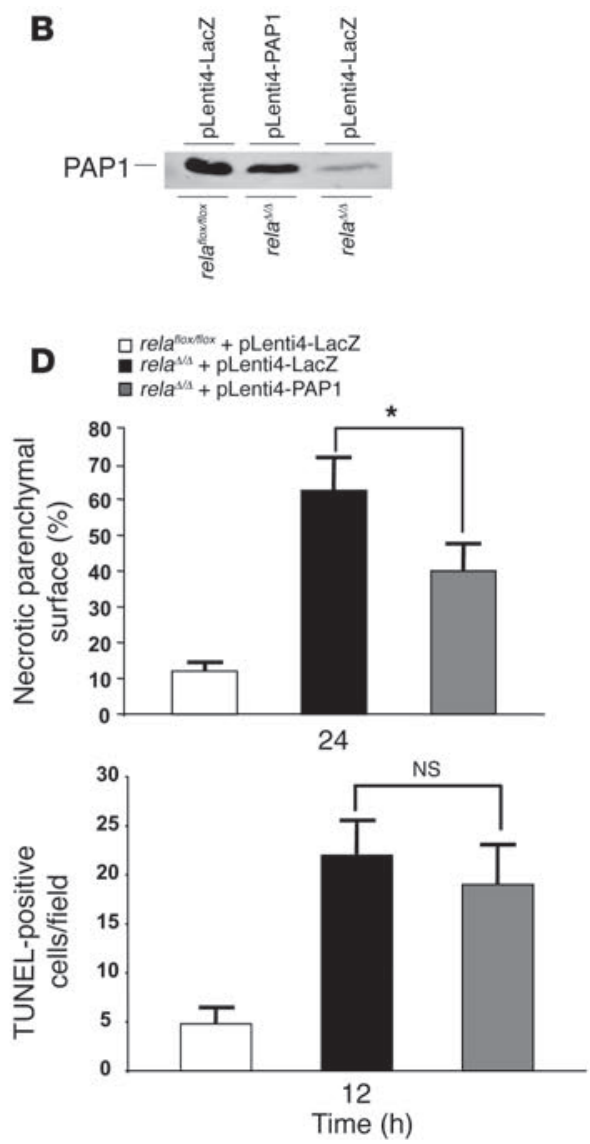

Figure 8

Protective effect of PAP1 on cerulein-induced pancreatitis in rela ${ }^{\Delta / \Delta}$ mice. (A) Lentivirus harboring the full-length cDNA of murine PAP1 was generated in HEK 293T cells and injected i.p. into rela ${ }^{\Delta / \Delta}$ mice to express PAP1 (pLenti4-PAP1) in the pancreas (circles). Four age- and sexmatched mice were used. Littermate control mice were infected with lentivirus (pLenti4-LacZ) containing the lacZ gene. Mice were subjected to cerulein-induced pancreatitis (arrows) 7 days after infection and then were sacrificed 12 and 24 hours after the first cerulein injection. (B) Pancreatic homogenates were obtained 12 hours after the first cerulein injection and analyzed for PAP1 expression. (C) Representative H\&Estained sections of pancreata and lungs from mice treated as in A. Original magnification, $\times 100$. (D) To assess the extent of tissue injury, necrosis and apoptosis were evaluated. Areas of necrotic parenchymal surface were measured and quantified. TUNEL assay was used to determine the apoptotic index of the pancreas. Values are mean \pm SD for independent animals $(n=4)$. ${ }^{\star} P<0.05$.

longed activation of the MAPK modules in their system $(24,38)$. MAPK modules are known to be transiently activated during cerulein-induced pancreatitis (25-31). Inhibition of these modules has been associated with an improvement in the outcome during AP $(27,39-41)$. By analyzing these pathways in our mouse model, we also detected a prolonged activation of MAPK modules (ERK1/2 [p42/44], p38, and SAPK [p46/54]) during inflammation in the rela ${ }^{\Delta / \Delta}$ pancreas (Figure 4). Taken together, our data and the results from these previous studies suggest that functional RelA/p65 is required to prevent cell death in the inflamed pancreas.

Intracellular conversion of zymogens to their activated forms is a critical step in the initiation of AP. It has been suggested that premature intra-acinar activation of trypsinogen catalyzes the intrapancreatic activation of digestive zymogens and pancreatic autodigestion in experimental animal models as well as in humans, although other studies discussed the dispensability of trypsin activity in this scenario (42-47). Because cleavage of trypsinogen and activation of NF- $\mathrm{KB} / \mathrm{Rel}$ display similar kinetics, previous studies assessed the relationship between trypsinogen activation and NF-кB/Rel induction $(48,49)$. We found that early activation of trypsinogen was not affected in rela ${ }^{\Delta / \Delta}$ mice compared with littermate controls, while late activation was dramatically increased in $r e l a^{\Delta / \Delta}$ mice. This finding demonstrates that the initiation of trypsinogen activation is independent of NF- $\mathrm{\kappa B} /$ Rel, as previously proposed $(50,51)$. Late, pronounced conversion of trypsinogen to trypsin might result from the increased tissue damage and nonspecific activation of serine proteases. Pronounced injury in the pancreata of rela $a^{\Delta / \Delta}$ mice was not a consequence of increased early trypsin activity, because trypsin activity in these mice was even lower 3 hours after the onset of AP. Therefore, other mechanisms must account for the protective effects mediated by NF-кB/Rel.

To identify potential protective NF- $\mathrm{KB} /$ Rel target genes, we performed microarray analysis using the pancreata from $\mathrm{rela}^{\Delta / \Delta}$ mice and from control littermates. We found that PAP1 was downregulated in unstimulated pancreas and was not induced during AP in $r e l a^{\Delta / \Delta}$ mice. Several functions have been proposed for PAP1 $(6,10,52)$. PAP1 prevented apoptosis and necrosis following oxidative stress or TNF- $\alpha$ stimulation in an AR42J pancreatic acinar cell line $(12,53,54)$. Antiinflammatory activity has been attributed to PAP1 in AR42J cells and in RAW cells, in which exogenous 
A

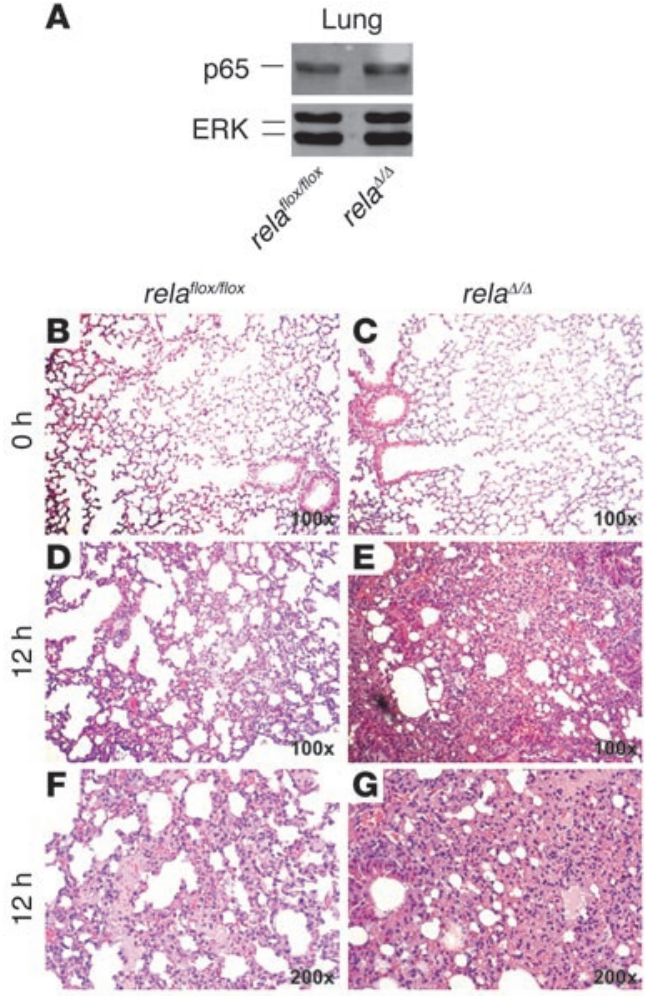

H

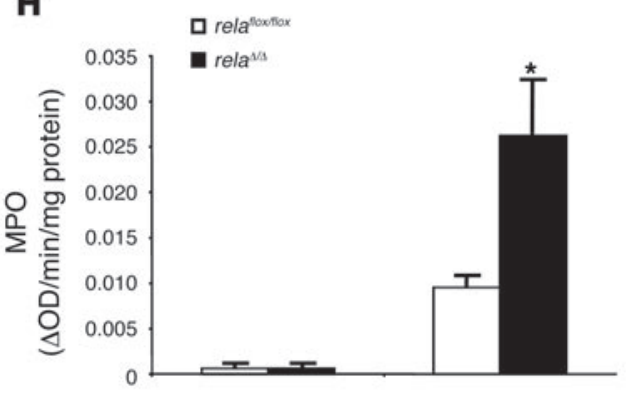

I

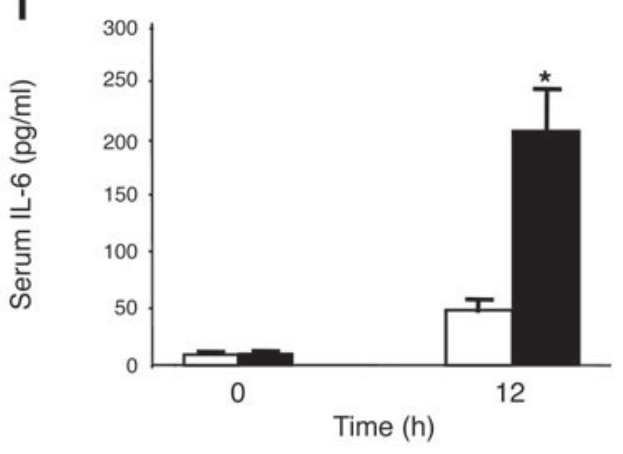

Figure 9

Pancreas-specific ablation of RelA/p65 promotes systemic complications and multiorgan dysfunction syndrome. (A) Expression of RelA/p65 in lung tissue of rela flox/flox and rela ${ }^{\Delta / \Delta}$ mice was assessed by subjecting $20 \mu \mathrm{g}$ of lung whole cell lysates to Western blot analysis. (B-G) At the indicated times after cerulein injection, lung tissue was removed, embedded in paraffin, and stained with $\mathrm{H} \& \mathrm{E}$. Higher magnification of representative H\&E stains

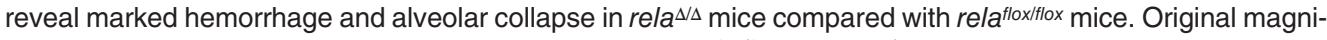
fication, $\times 100(\mathbf{B}-\mathbf{E}) ; \times 200(\mathbf{F}$ and $\mathbf{G})$. (H) Lung tissue of relaflox/flox and rela ${ }^{\Delta / \Delta}$ mice was removed at the indicated time points and used to determine MPO enzyme activity. (I) Serum concentrations of IL-6 were determined at the time points indicated. Data represent the mean \pm SD of 5 animals. ${ }^{*} P<0.05$ versus rela ${ }^{\text {flox }}$ fllox.

purified PAP1 inhibited both TNF- $\alpha$-mediated NF- $\kappa$ B/Rel activation and IL- 6 and TNF- $\alpha$ production $(11,12)$. In this context, it is conceivable that the lack of PAP1 in rela ${ }^{\Delta / \Delta}$ mice causes prolonged activation of NF- $\kappa \mathrm{B} /$ Rel in inflammatory cells. Indeed, in contrast to relaflox/flox mice, we detected late NF- $\mathrm{BB} /$ Rel activation in rela ${ }^{\Delta / \Delta}$ mice (data not shown). Among other factors, prolonged activation of NF-кB/Rel in inflammatory cells might be responsible for enhanced systemic complications during AP in rela ${ }^{\Delta / \Delta}$ mice (11). Although lentivirus-mediated expression of PAP1 in rela ${ }^{\Delta / \Delta}$ mice slightly decreased the characteristic lung inflammation as evaluated morphologically, this might be simply a manifestation of the more severe pancreatitis in rela $\mathrm{a}^{\Delta / \Delta}$ mice, although it has previously been shown that PAP1 administration enhances pancreatitis-associated lung inflammation in rats (55). In general, our data support a beneficial role for PAP in AP, as previously suggested in studies of rats (56). First, siRNA-mediated knockdown of PAP1 resulted in increased infiltration and necrosis in nontransgenic wild-type mice. Second, lentivirus-mediated complementation of PAP1 in $\mathrm{rela}^{\Delta / \Delta}$ mice significantly reduced the extent of necrosis, while it had no significant effect on apoptosis. Therefore, other RelA/p65dependent mechanisms involved in mediating apoptosis might contribute to increased programmed cell death. Indeed, impaired upregulation of $\mathrm{Bcl}-\mathrm{X}_{\mathrm{L}}$ in the pancreas with functional inactive matory processes in the pancreas. The contribution of NF-kB/Rel activity in other compartments during acute pancreatitis has to be elucidated in further studies using genetic approaches.

\section{Methods}

Generation of Ptf1a-creext and relaflox/flox mice. The relaflox/flox mice were generated according to a previously described 2 -step procedure (59). A targeting vector was constructed to insert a modified loxP site (60) and the selection marker genes PGK-neo and TK into the rela genomic locus. Two of the loxP sites flank neo, and the third is located between exons 10 and 11 of the rela gene. The mouse rela gene fragments were isolated from a $129 / \mathrm{Sv}$ mouse genomic library in $\lambda$ DASHII (Stratagene). The floxed fragment of rela contains exons 7-10, which code a part of the Rel homology domain and the nuclear localization site. After electroporation, the transfected ES cells were selected with G418 $(0.2 \mathrm{mg} / \mathrm{ml})$, and recombinants were identified by PCR analysis. One recombinant was further cultured and then transfected with a Cre recombinase expression vector to delete the selection marker genes and to generate relaflox/+ ES cells. The relaflox/+ ES cells were screened by Southern blotting using a probe external to the $5^{\prime}$ end of the targeting construct. Two relaflox/+ ES clones were injected into C57BL/ 6 blastocysts. The progeny with the highest degree of chimerism were crossed with C57BL $/ 6$ mice to derive the experimental lines. 


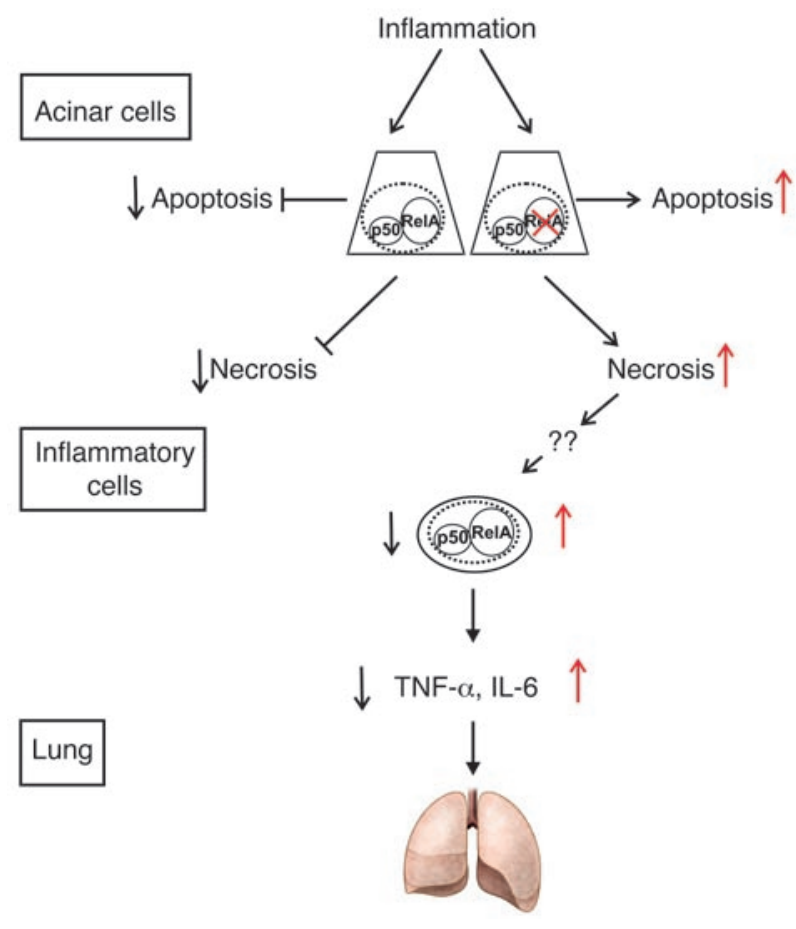

To drive Cre expression in the exocrine compartment of the pancreas, we constructed a Ptfla-cre ${ }^{e x 1}$ mouse by replacing exon 1 with the gene encoding for Cre recombinase (61). To assess Cre activity, Ptf1a-cre $e^{e x 1}$ mice were crossed to Gt (ROSA) 26Sortm1Sor (R26R) mice, which carry a modified lac $Z$ gene driven by the cell type-independent ROSA26 promoter (62). Cre excises a stop cassette upstream of $l a c Z$ and thereby activates expression of $\beta$-galactosidase. The Ptf1a-cre $e^{e x 1}$ mice exhibited LacZ expression and revealed Cre activity in nearly all acinar and some ductal cells (Supplemental Figure 1). The relaflox/flox mice were crossed to Ptfla-cre $e^{e x 1}$ mice to generate rela $a^{\Delta / \Delta}$ mice. The relatox/flox and Ptfla-cre $e^{e x I}$ mice were used as control mice. PCR on tail DNA was used to confirm the presence of the mutated rela allele and the Cre recombinase gene. The presence of mutated or wild-type rela allele was tested under standard PCR conditions using the following specific primers: 5'-GAGCGCATGCCTAGCACCAG-3'; 5'-GTGCACTGCATGCGTGCAG-3'. The presence of the Cre recombinase gene was tested by using the following specific primers: 5 '-GTCCAATTTACTGACCGTACACCAA-3'; 5'-CCTCGAAGGCGTCGTTGATGGACTGCA-3'.

Southern blot analysis. DNA from various tissues of mice was digested with $B g l I I$ and then separated on agarose gel electrophoresis, blotted to nylon membrane, and detected with the radioactive 5 ' flanking external probe (431 bp).

Pancreatitis models. For cerulein-induced pancreatitis, age- and sexmatched littermates were fasted for 18 hours but provided with water ad libitum. The genetic background of control and experimental animals was identical (C57BL/6) for all experiments. Mice received 12 hourly i.p. injections of saline (control) or $50 \mu \mathrm{g} / \mathrm{kg}$ cerulein (Sigma-Aldrich) in saline. The mice were followed for up to 24 hours. The L-arginine model of pancreatitis in nonfasted mice was induced by i.p. application of $4 \mathrm{~g} / \mathrm{kg}$ arginine. A sterile solution of L-arginine hydrochloride (8\%; Sigma-Aldrich) was prepared in normal saline and the $\mathrm{pH}$ was adjusted to 7.0. Mice received 2 hourly injections of L-arginine ( $4 \mathrm{~g} / \mathrm{kg}$ ), while controls were administered saline. Seventy-two hours after the first injection, mice were sacrificed, and the pancreas together with the lung were removed for morphological analysis. Blood from the tail vein was drawn at varying time points. Mice were handled according to protocols that

\section{Figure 10}

Model for RelA/p65 function in AP. During inflammation in the pancreas, acinar cells undergo apoptotic and necrotic cell death. Cellular constituents are released from injured necrotic acinar cells following stimulation with cerulein. This feature is enhanced when functional RelAp65 is lacking. Increased acinar cell necrosis causes infiltration by mononuclear cells, which are activated to produce cytokines such as IL-6 and TNF- $\alpha$ that cause systemic effects including lung inflammation.

follow the national guidelines for ethical animal treatment and were approved by the Zentrum für präklinische Forschung (ZPF) of the Technical University of Munich.

Preparation of serum and tissue samples. Mice were sacrificed at time points between 1 and 24 hours after the first injection of cerulein. Whole blood samples were centrifuged at $4{ }^{\circ} \mathrm{C}$, and serum was stored at $-80^{\circ} \mathrm{C}$ for further studies. Serum was used for IL- 6 analysis (mIL-6 ELISA; R\&D Systems) and for LDH and amylase analysis according to standard procedures. Tissues from the pancreas, liver, and lung were removed, placed on ice, immediately frozen in liquid nitrogen, and stored at $-80^{\circ} \mathrm{C}$. Trypsin activity was measured as described by Halangk et al. (63). MPO activity in lung and pancreas samples was determined as previously described (64).

Western blot analysis and EMSA. For Western blot analysis, cellular proteins were prepared from mouse liver, lung, and pancreas by standard methods. Protein extracts were subjected to SDS-polyacrylamide gel electrophoresis and blotted to nitrocellulose membranes. The membranes were probed with the following antibodies: anti-p65, anti-IкB $\alpha$, anti-IкB $\beta$, anti-ERK1, and anti-ERK2 (Santa Cruz Biotechnology Inc.); anti-IKK1, anti-IKK2, and anti-IKKg (BD Biosciences - Pharmingen); and anti-phosphorylated I $\mathrm{B} \alpha$, anti-phosphorylated $\mathrm{p} 42 / 44$, anti-phosphorylated p38, anti-p38, anti-p46/57, anti-phosphorylated p46/57, and anti-p50 (Cell Signaling). PAP1 was generated by immunizing rabbits with the $\mathrm{N}$-terminal peptide sequence (GEDSLKNIPSARISC) of the mature protein (GenBank accession no. NP_035166). A low-molecular weight protein marker was used to determine the size of detected bands in the Western blot (LMW-SDS Marker Kit, GE HealthCare). For EMSA, nuclear extracts were prepared and binding reactions were performed as described previously (64). A ${ }^{32} \mathrm{P}$-labeled oligonucleotide representing an NF- $\mathrm{KB}$ consensus site was used as the probe: sense, $5^{\prime}$-AGCTTGGGGACTTTCCACTAGTACG- $3^{\prime}$; antisense, 5'-AATTCGTACTAGTGGAAAGTCCCCA-3'.

In vivo siRNA treatment and lentiviral infection. Mice were injected i.p. every other day (2 total injections) with saline, with 1 of 2 siRNA probes (PAP1 288 or PAP1 90; 5 mg/kg body weight), or with SDI. Pancreatitis was induced by cerulein injection, and mice were sacrificed 24 hours after the first injection. The siRNA were synthesized by MWG-Biotech AG. The sequence of the 2 PAP1 siRNAs and nonspecific SDI were as follows: SDI, NNCAGUCGCGUUUGCGACUGG; PAP1 90, NNGAAUAUACCCUCCGCACGC; PAP1 288, NNCAGCUACCAAUACACUUGG.

Generation of the lentivirus containing the lac $Z$ gene or the full gene sequence for PAP1 and the preparation of viral stocks was performed according to established protocols using ViraPower Lentiviral Expression System (Invitrogen). In brief, murine PAP1 cDNA from EST clone IMAGp998C0712539 (Melton mixed library; RZPD German Resource Center for Genome Research) was cloned into pLenti4/TO/V5-Dest (Invitrogen), generating the lentivirus pLenti4-PAP1. The human embryonic kidney cell line 293T was cultured in DMEM supplemented with $10 \%$ fetal calf serum. Viral particles were produced by cotransfection of pLenti4-PAP1 or pLenti4-LacZ with pLP1, pLP2 and pLP/VSVG plasmids (all from Invitrogen) into $293 \mathrm{~T}$ cells using Lipofectamine 2000 (Invitrogen). Culture medium was replaced by serum-free DMEM 6 hours after transfection. Cell supernatants were harvested 24 and 36 hours later, filtered through a $0.45-\mu \mathrm{m}$ 
filtration system, and concentrated by ultracentrifugation. Lentiviral vector titers were determined by HIV-1 p24 ELISA (PerkinElmer). Mice were infected with equal viral concentrations every third day (3 injections total) and followed 7 days before the initiation of pancreatitis.

Histology, immunohistochemistry, and TUNEL. For morphological analyses, pancreatic and lung tissues were removed, immediately immersed in $4 \%$ neutral phosphate-buffered paraformaldehyde for 12 hours, embedded in paraffin, and sectioned $(5 \mu \mathrm{m})$. Sections were processed for immunohistochemistry as described previously (14). Frozen pieces of pancreas were embedded in Tissue-Tek (Sakura), and $10-\mu \mathrm{m}$ sections were processed for immunohistochemistry. The TUNEL assay was performed using the in situ cell death kit (POD; Roche Diagnostics) according to the manufacturer's instructions. Antibody against TNF- $\alpha$ was purchased from Santa Cruz Biotechnology Inc., antibody against $\beta$-galactosidase was purchased from Sigma-Aldrich, and the Gr-1 antibody was purchased from BD Biosciences - Pharmingen.

Quantification of necrosis. Pancreatic tissue sections were stained with H\&E. Necrotic cells with swollen cytoplasm, loss of plasma membrane integrity, and leakage of organelles into the interstitium were counted and evaluated by 2 researchers in a blinded manner. Necrosis was expressed as the percentage of examined pancreatic parenchyma.

Histopathologic score. For evaluation of lung inflammation during pancreatitis we randomly chose 10 microscopic fields for each mouse $(n=4)$. Alveolar wall thickening was scored by 2 researchers in a blinded manner as follows: 0 , no lung involvement; 1 , mild $(<25 \%)$ lung involvement; 2 , moderate (25\%-50\%) lung involvement; 3 , severe $(50 \%-75 \%)$ lung involvement.

Microarray analysis of gene expression. Total pancreatic RNA $(8 \mu \mathrm{g})$ was labeled and hybridized to Affymetrix MOE430A GeneChips according to the manufacturer's instructions. Two biological replicates per mouse line were analyzed. Hierarchical clustering was performed using the program Genesis (release 1.6.0 Beta 1; ref. 65).

Chromatin immunoprecipitation. After stimulation, pancreatic tissues were fixed at room temperature by the addition of formaldehyde (1\%). Pancreatic tissues were washed twice with ice-cold PBS, lysed in L1 buffer (50 mM Tris, pH 8.0; 2 mM EDTA; 0.1\% Nonidet P-40; 10\% glycerol; and a protease inhibitor cocktail diluted 1:200, P-8340, from Sigma-Aldrich), and then transferred to a reaction tube. Nuclei were pelleted at $1,000 \mathrm{~g}$ and resuspended in L2 buffer (50 mM Tris, pH 8.0; 5 mM EDTA; 0.1\% SDS; and protease inhibitor cocktail diluted 1:200). Chromatin was sheared into fragments of an average size of $400 \mathrm{bp}$ with a sonicator $(3 \times 30 \mathrm{~s}$ at $60 \%$ maximum power; Bandelin), centrifuged to pellet debris, and diluted 10-fold with dilution buffer (50 mM Tris, pH 8.0; 0.5 mM EDTA; $0.2 \mathrm{M}$ $\mathrm{NaCl} ; 0.5 \%$ Nonidet P-40; and protease inhibitor cocktail diluted 1:200). Each sample was precleared for 3 hours with $80 \mu \mathrm{l}$ of salmon sperm-saturated protein A agarose (Upstate Biotechnology). Immunoprecipitations were performed overnight at $4{ }^{\circ} \mathrm{C}$. The anti-p 65 and anti-H4 antibodies were from Santa Cruz Biotechnology Inc. Antibody-chromatin complexes were collected with $80 \mu \mathrm{l}$ of salmon sperm-saturated protein A agarose

1. Baron, T.H., and Morgan, D.E. 1999. Acute necrotizing pancreatitis. N. Engl. J. Med. 340:1412-1417.

2. Whitcomb, D.C. 2006. Clinical practice. Acute pancreatitis. N. Engl. J. Med. 354:2142-2150.

3. Geokas, M.C., and Rinderknecht, H. 1974. Free proteolytic enzymes in pancreatic juice of patients with acute pancreatitis. Am. J. Dig. Dis. 19:591-598.

4. Bialek, R., Willemer, S., Arnold, R., and Adler, G. 1991. Evidence of intracellular activation of serine proteases in acute cerulein-induced pancreatitis in rats. Scand. J. Gastroenterol. 26:190-196.

5. Naruse, S. 2003. Molecular pathophysiology of pancreatitis. Intern. Med. 42:288-289.

6. Bodeker, H., Fiedler, F., Keim, V., Dagorn, J.C., and Iovanna, J.L. 1998. Pancreatitis-associated protein
(Upstate Biotechnology) for 1 hour and washed 3 times each with highsalt buffer (20 mM Tris, pH 8.0; 2 mM EDTA; $0.5 \mathrm{M} \mathrm{NaCl}$; 0.1\% SDS; and $1 \%$ Nonidet P-40), LiCl buffer (20 mM Tris, pH 8.0; 1 mM EDTA; $250 \mathrm{mM} \mathrm{LiCl} ; 0.5 \%$ Nonidet P-40; and $0.5 \%$ sodium deoxycholate), and $1 \times \mathrm{TE}$ (10 mM Tris, $\mathrm{pH} 8.0$, and $1 \mathrm{mM}$ EDTA). Immune complexes were extracted with $1 \times \mathrm{TE}$ containing $1 \% \mathrm{SDS}$ at $65^{\circ} \mathrm{C}$. After addition of $\mathrm{NaCl}(300 \mathrm{mM}$ final concentration), protein-DNA crosslinks were reverted overnight at $65^{\circ} \mathrm{C}$. Proteins were digested with proteinase K for 2 hours. The DNA was extracted with phenol/chloroform and precipitated with ethanol. One-twentieth of the DNA was used in each PCR (35-38 cycles) with the following primers: $\kappa B 1$ site, $5^{\prime}$-TCATTGGAGGTTGTTGGAGGGAAG-3' and 5'-TCCTAGGAATCTCTTTATCTTCCCGG-3'; кB2 site, 5'-GGCACAAATTATGCTATGACATAGTTTGTAAAA- $3^{\prime}$ and $5^{\prime}$-AACTTACACCTACAATTTTTAATCTGCTCAGTTC-3'.

Real-time PCR. Total tissue RNA was extracted using the RNeasy kit (QIAGEN) according to the manufacturer's instructions. Total RNA was quantified by ultraviolet absorption and reversibly transcribed into cDNA using SuperScript II reverse transcriptase (Invitrogen) and Oligo$\mathrm{dT}$ primers (Invitrogen) according to the manufacturer's instructions. Transcribed cDNA was further analyzed by real-time PCR as described by Chen et al. (58). The following primer sequences were used: PAP1 mRNA, forward 5'-CTCCTGCCTGATGCTCTTAT-3', reverse 5'-TTGTTACTCCACTCCCATCC-3'; cyclophilin mRNA, forward 5'-ATGGTCAACCCCACCGTGT-3', reverse 5'-TTCTGCTGTCTTTGGAACTTTGTC-3'. All values were normalized to the level of cyclophilin cDNA.

Statistics. Data are expressed as mean \pm SD. Differences were analyzed by Student's $t$ test. In all cases, sample sizes were chosen to produce statistically unambiguous results. A $P$ value of 0.05 or less was considered significant.

\section{Acknowledgments}

We are deeply indebted to Karen Dlubatz, Kornelia Kellnberger, and Andrea Lohner for technical assistance. We also thank Ashok Saluja (University of Massachusetts Medical School, Worcester, Massachusetts, USA) for providing the protocol for the L-arginine model of pancreatitis. The help of Jörg Mages (Technical University of Munich) in Affymetrix Gene Chip analysis is gratefully acknowledged. This work was supported by German Research Foundation grants SFB 576, TP A10 (to R.M. Schmid) and FOR535, PF301/8-2 (to A. Pfeifer).

Received for publication July 27, 2006, and accepted in revised form March 30, 2007.

Address correspondence to: Roland M. Schmid, Second Department of Internal Medicine, Klinikum rechts der Isar, Technical University of Munich, Ismaninger Strasse 22, Munich 81675, Germany. Phone: 49-89-4140-2250; Fax: 49-89-4140-4871; E-mail: roland.schmid@lrz.tu-muenchen.de. is upregulated in mouse pancreas during acute pancreatitis. Digestion. 59:186-191.

7. Keim, V., Iovanna, J.L., Rohr, G., Usadel, K.H., and Dagorn, J.C. 1991. Characterization of a rat pancreatic secretory protein associated with pancreatitis. Gastroenterology. 100:775-782.

8. Iovanna, J.L., Keim, V., Michel, R., and Dagorn, J.C. 1991. Pancreatic gene expression is altered during acute experimental pancreatitis in the rat. Am. J. Physiol. 261:G485-G489.

9. Graf, R., et al. 2005. Exocrine meets endocrine: pancreatic stone protein and regenerating protein - two sides of the same coin. J. Surg. Res. 133:113-120.

10. Keim, V., Willemer, S., Iovanna, J.L., Adler, G., and
Dagorn, J.C. 1994. Rat pancreatitis-associated protein is expressed in relation to severity of experimental pancreatitis. Pancreas. 9:606-612.

11. Folch-Puy, E., Granell, S., Dagorn, J.C., Iovanna, J.L., and Closa, D. 2006. Pancreatitis-associated protein I suppresses NF-kappa B activation through a JAK/STAT-mediated mechanism in epithelial cells. J. Immunol. 176:3774-3779.

12. Vasseur, S., et al. 2004. p8 improves pancreatic response to acute pancreatitis by enhancing the expression of the anti-inflammatory protein pancreatitis-associated protein I. J. Biol. Chem. 279:7199-7207.

13. Gukovsky, I., Gukovskaya, A.S., Blinman, T.A., Zaninovic, V., and Pandol, S.J. 1998. Early NF-kap- 
$\mathrm{paB}$ activation is associated with hormone-induced pancreatitis. Am. J. Physiol. 275:G1402-G1414.

14. Steinle, A.U., Weidenbach, H., Wagner, M., Adler, G., and Schmid, R.M. 1999. NF-kappaB/Rel activation in cerulein pancreatitis. Gastroenterology. 116:420-430

15. Karin, M., and Lin, A. 2002. NF-kappaB at the crossroads of life and death. Nat. Immunol. 3:221-227.

16. Karin, M., Yamamoto, Y., and Wang, Q.M. 2004. The IKK NF-kappa B system: a treasure trove for drug development. Nat. Rev. Drug Discov. 3:17-26.

17. Karin, M. 2006. Nuclear factor-kappaB in cancer development and progression. Nature. 441:431-436.

18. Beg, A.A., Sha, W.C., Bronson, R.T., Ghosh, S., and Baltimore, D. 1995. Embryonic lethality and liver degeneration in mice lacking the RelA component of NF-kappa B. Nature. 376:167-170.

19. Krapp, A., et al. 1996. The p48 DNA-binding subunit of transcription factor PTF1 is a new exocrine pancreas-specific basic helix-loop-helix protein. EMBO J. 15:4317-4329.

20. Krapp, A., et al. 1998. The bHLH protein PTF1-p48 is essential for the formation of the exocrine and the correct spatial organization of the endocrine pancreas. Genes Dev. 12:3752-3763.

21. Kawaguchi, Y., et al. 2002. The role of the transcriptional regulator Ptf1a in converting intestinal to pancreatic progenitors. Nat. Genet. 32:128-134.

22. Dawra, R., et al. 2006. Development of a new mouse model of acute pancreatitis induced by administration of L-arginine. Am. J. Physiol. Gastrointest. Liver Physiol. 292:G1009-G1018.

23. Schafer, C., and Williams, J.A. 2000. Stress kinases and heat shock proteins in the pancreas: possible roles in normal function and disease. J. Gastroenterol. 35:1-9.

24. Sakon, S., et al. 2003. NF-kappaB inhibits TNFinduced accumulation of ROS that mediate prolonged MAPK activation and necrotic cell death. EMBO J. 22:3898-3909.

25. Williams, J.A., et al. 2002. Cholecystokinin activates a variety of intracellular signal transduction mechanisms in rodent pancreatic acinar cells. Pharmacol. Toxicol. 91:297-303.

26. Wagner, A.C., Metzler, W., Hofken, T., Weber, H., and Goke, B. 1999. p38 map kinase is expressed in the pancreas and is immediately activated following cerulein hyperstimulation. Digestion. 60:41-47.

27. Hofken, T., Keller, N., Fleischer, F., Goke, B., and Wagner, A.C. 2000. Map kinase phosphatases (MKPs) are early responsive genes during induction of cerulein hyperstimulation pancreatitis. Biochem Biophys. Res. Commun. 276:680-685.

28. Tapia, J.A., Ferris, H.A., Jensen, R.T., and Garcia, L.J. 1999. Cholecystokinin activates PYK2/CAKbeta by a phospholipase C-dependent mechanism and its association with the mitogen-activated protein kinase signaling pathway in pancreatic acinar cells. J. Biol. Chem. 274:31261-31271.

29. Schafer, C., et al. 1998. A role for the p38 mitogen-activated protein kinase/Hsp 27 pathway in cholecystokinin-induced changes in the actin cytoskeleton in rat pancreatic acini. J. Biol. Chem. 273:24173-24180.

30. Dabrowski, A., Groblewski, G.E., Schafer, C., Guan, K.L., and Williams, J.A. 1997. Cholecystokinin and EGF activate a MAPK cascade by different mechanisms in rat pancreatic acinar cells. Am. J. Physiol. 273:C1472-C1479.
31. Minutoli, L., et al. 2004. Protective effects of SP600125 a new inhibitor of c-jun N-terminal kinase (JNK) and extracellular-regulated kinase (ERK1/2) in an experimental model of ceruleininduced pancreatitis. Life Sci. 75:2853-2866.

32. Nakamichi, I., et al. 2005. Hemin-activated macrophages home to the pancreas and protect from acute pancreatitis via heme oxygenase- 1 induction. J. Clin. Invest. 115:3007-3014. doi:10.1172/ JCI24912.

33. Gukovskaya, A.S., and Pandol, S.J. 2004. Cell death pathways in pancreatitis and pancreatic cancer. Pancreatology. 4:567-586.

34. Gukovskaya, A.S., et al. 1996. Mechanisms of cell death after pancreatic duct obstruction in the opossum and the rat. Gastroenterology. 110:875-884.

35. Kaiser, A.M., Saluja, A.K., Sengupta, A., Saluja, M., and Steer, M.L. 1995. Relationship between severity, necrosis, and apoptosis in five models of experimental acute pancreatitis. Am. J. Physiol. 269:C1295-C1304.

36. Frossard, J.L., et al. 2003. Severe acute pancreatitis and reduced acinar cell apoptosis in the exocrine pancreas of mice deficient for the $\mathrm{C} x 32$ gene. Gastroenterology. 124:481-493.

37. Hahm, K.B., et al. 1998. Induction of apoptosis with an extract of Artemisia asiatica attenuates the severity of cerulein-induced pancreatitis in rats. Pancreas. 17:153-157.

38. Fiers, W., Beyaert, R., Declercq, W., and Vandenabeele, P. 1999. More than one way to die: apoptosis, necrosis and reactive oxygen damage. Oncogene. 18:7719-7730.

39. Wagner, A.C., Mazzucchelli, L., Miller, M., Camoratto, A.M., and Goke, B. 2000. CEP-1347 inhibits caerulein-induced rat pancreatic JNK activation and ameliorates caerulein pancreatitis. Am. J. Physiol. Gastrointest. Liver Physiol. 278:G165-G172.

40. Perides, G., et al. 2005. Secretin differentially sensitizes rat pancreatic acini to the effects of supramaximal stimulation with caerulein. Am. J. Physiol. Gastrointest. Liver Physiol. 289:G713-G721.

41. Sharma, A., et al. 2005. Protection against acute pancreatitis by activation of protease-activated receptor-2. Am. J. Physiol. Gastrointest. Liver Physiol. 288:G388-G395.

42. Hofbauer, B., et al. 1998. Intra-acinar cell activation of trypsinogen during caerulein-induced pancreatitis in rats. Am. J. Physiol. 275:G352-G362.

43. Saluja, A.K., et al. 1997. Cerulein-induced in vitro activation of trypsinogen in rat pancreatic acini is mediated by cathepsin B. Gastroenterology. 113:304-310.

44. Grady, T., Saluja, A., Kaiser, A., and Steer, M. 1996. Edema and intrapancreatic trypsinogen activation precede glutathione depletion during caerulein pancreatitis. Am. J. Physiol. 271:G20-G26.

45. Witt, H., et al. 2000. Mutations in the gene encoding the serine protease inhibitor, Kazal type 1 are associated with chronic pancreatitis. Nat. Genet. 25:213-216.

46. Whitcomb, D.C., et al. 1996. Hereditary pancreatitis is caused by a mutation in the cationic trypsinogen gene. Nat. Genet. 14:141-145.

47. Nathan, J.D., et al. 2005. Transgenic expression of pancreatic secretory trypsin inhibitor-I ameliorates secretagogue-induced pancreatitis in mice. Gastroenterology. 128:717-727.

48. Han, B., Ji, B., and Logsdon, C.D. 2001. CCK inde- pendently activates intracellular trypsinogen and NF-kappaB in rat pancreatic acinar cells. Am. J. Physiol. Cell Physiol. 280:C465-C472.

49. Tando, Y., et al. 2002. Induction of IkappaB-kinase by cholecystokinin is mediated by trypsinogen activation in rat pancreatic lobules. Digestion. 66:237-245.

50. Singh, V.P., et al. 2001. Phosphatidylinositol 3kinase-dependent activation of trypsinogen modulates the severity of acute pancreatitis. J. Clin. Invest. 108:1387-1395. doi:10.1172/JCI200112874.

51. Hietaranta, A.J., et al. 2001. Relationship between NF-kappaB and trypsinogen activation in rat pancreas after supramaximal caerulein stimulation. Biochem. Biophys. Res. Commun. 280:388-395.

52. Iovanna, J.L., and Dagorn, J.C. 2005. The multifunctional family of secreted proteins containing a C-type lectin-like domain linked to a short N-terminal peptide. Biochim. Biophys. Acta. 1723:8-18.

53. Malka, D., et al. 2000. Tumor necrosis factor alpha triggers antiapoptotic mechanisms in rat pancreatic cells through pancreatitis-associated protein I activation. Gastroenterology. 119:816-828.

54. Ortiz, E.M., et al. 1998. The pancreatitis-associated protein is induced by free radicals in AR4-2J cells and confers cell resistance to apoptosis. Gastroenterology. 114:808-816.

55. Folch-Puy, E., et al. 2003. The pancreatitis-associated protein induces lung inflammation in the rat through activation of TNFalpha expression in hepatocytes. J. Pathol. 199:398-408.

56. Zhang, H., Kandil, E., Lin, Y.Y., Levi, G., and Zenilman, M.E. 2004. Targeted inhibition of gene expression of pancreatitis-associated proteins exacerbates the severity of acute pancreatitis in rats. Scand. J. Gastroenterol. 39:870-881.

57. Greten, F.R., et al. 2004. IKKbeta links inflammation and tumorigenesis in a mouse model of colitisassociated cancer. Cell. 118:285-296.

58. Chen, L.W., et al. 2003. The two faces of IKK and NFkappaB inhibition: prevention of systemic inflammation but increased local injury following intestinal ischemia-reperfusion. Nat. Med. 9:575-581.

59. Gu, H., Marth, J.D., Orban, P.C., Mossmann, H., and Rajewsky, K. 1994. Deletion of a DNA polymerase beta gene segment in T cells using cell typespecific gene targeting. Science. 265:103-106.

60. Hoess, R.H., Wierzbicki, A., and Abremski, K. 1986. The role of the loxP spacer region in P1 site-specific recombination. Nucleic Acids Res. 14:2287-2300.

61. Nakhai, H., et al. 2007. Ptf1a is essential for the differentiation of GABAergic and glycinergic amacrine cells and horizontal cells in the mouse retina. Development. 134:1151-1160.

62. Soriano, P. 1999. Generalized lacZ expression with the ROSA26 Cre reporter strain. Nat. Genet. 21:70-71.

63. Halangk, W., et al. 2000. Role of cathepsin B in intracellular trypsinogen activation and the onset of acute pancreatitis. J. Clin. Invest. 106:773-781.

64. Geisler, F., Algul, H., Riemann, M., and Schmid, R.M. 2005. Questioning current concepts in acute pancreatitis: endotoxin contamination of porcine pancreatic elastase is responsible for experimental pancreatitis-associated distant organ failure. J. Immunol. 174:6431-6439.

65. Sturn, A., Quackenbush, J., and Trajanoski, Z. 2002. Genesis: cluster analysis of microarray data. Bioinformatics. 18:207-208. 